\section{Palobra}

acceso $\odot$ abierto

Cómo citar: Fernández, A. (2020).

Solidaridad y humor, caricaturas y memes en torno a un terremoto. Palobra, 20(2), 150-171. 10.32997/2346-2884-vol.20-num.2-2020-3313

Recibido: 18 de mayo de 2020 .

Aprobado: 12 de agosto de 2020.

Autor de correspondencia:

Anna María Fernández Poncela

fpam1721@correo.xoc.uam

Editora: Rosario Blanco Bello. Universidad de Cartagena-Colombia.

Tipología IBN Publindex: Artículo de Investigación Científica.

\title{
Solidaridad y humor, caricaturas y memes en torno a un terremoto
}

\author{
Solidarity and humor, cartoons and memes \\ around an earthquake
}

Anna María Fernández Poncela

Universidad Autónoma de México, México,fpam1721@ correo.xoc.uam.mx

\begin{abstract}
RESUMEN
Este trabajo es un acercamiento al sismo de magnitud 7.1 en México, el 19 de septiembre del año 2017. En concreto una revisión de expresiones culturales y humorísticas que aparecen en los medios de comunicación y las redes digitales en torno al temblor: las caricaturas y los memes. Como resultado principal se señala el destacado papel de la solidaridad ante la tragedia y también la crítica política. Las emociones de amor y miedo, y de enojo, se mostraron junto a la empatía, como parte de transitar la tensión existente, de vincularse y consolarse, aliviar el estrés y mostrar comprensión y solidaridad.
\end{abstract}

Palabras clave: caricaturas; humor; memes; México; sismo.

\begin{abstract}
This work is an approach to the 7.1 magnitude earthquake in Mexico, on September 19, 2017. Specifically, a review of cultural and humorous expressions that appear in the media and digital networks around the earthquake: cartoons and memes The main result is the prominent role of solidarity in the face of tragedy and also political criticism. The emotions of love and fear, and of anger, were shown together with empathy, as part of navigating the existing tension, bonding and comforting, relieving stress and showing understanding and solidarity.
\end{abstract}

Keywords: cartoons; earthquake; humor; memes; Mexico.

\section{INTRODUCCIÓN}

En la vida el humor es importante, y esto vale para la cotidianidad como para ciertos momentos considerados determinantes en nuestro devenir por la existencia. El humor a veces nos consuela, otras veces nos energiza, siempre nos acompaña, y en general es, en cierto sentido, agradable y produce sensaciones y emociones satisfactorias. En el presente texto, se analiza el papel del humor originado en los días inmediatamente posteriores al sismo sufrido en México el día 19 de septiembre de 2017.

Para situar la importancia del sismo, según el Servicio Sismológico Nacional reportó un temblor "con magnitud 7.1 localizado en el límite estatal entre los 
estados de Puebla y Morelos, a $12 \mathrm{~km}$ al sureste de Axochiapan, Morelos y a $120 \mathrm{~km}$ de la Ciudad de México" (Sistema Sismológico Nacional -SSNa-, 2017, p.1). Tuvo lugar a las 13:14 horas ${ }^{1}$, sentido de forma importante en el centro del país, y en concreto en una de las tramas urbanas más pobladas del mundo, la ciudad de México y al área metropolitana. Grosso modo, decir que ese mismo día se registraron 34 derrumbes y luego se contabilizaron más de 6000 viviendas dañadas solo en la ciudad (Instituto de Investigaciones Legislativas (IIL), 2018). Se habla de 369 muertes, 228 en la ciudad, 74 en Morelos, 45 en Puebla, 15 en el Estado de México, 6 en Guerrero y 1 en Oaxaca, además de heridos, damnificados y afectados de una u otra forma (Ureste, 2017).

Sobre el contenido de este artículo, en primer lugar, se realiza una aproximación teórica sobre la relación entre el humor, la caricatura y los memes, así como, el humor en tiempos de desastres, para posteriormente, y a partir de la revisión de diversos memes y caricaturas que circularon en redes sociales y periódicos, entender las diferentes funciones que tuvieron y emociones que cubrieron estas expresiones comunicativas y culturales para la sociedad mexicana en medio de la tragedia.

\section{Objetivo y metodología}

El objetivo concreto de este texto -tras el abordaje teórico-conceptual del humor en la caricatura y los memes, y estos en los tiempos de desastres- es una revisión de memes y caricaturas en torno al 19-S, esto es, el terremoto que en 2017 movió y conmovió a México. En una sociedad como la mexicana en la cual se reitera que se burla de todo. ¿Qué tanto eso es cierto? ¿Qué transmitía el supuesto humor en esos momentos y ante las trágicas y traumáticas circunstancias vividas? ¿Se trató de un humor bañado por el afecto, desteñido de evasión o coloreado de crítica? ¿Qué emociones lo atravesaban, el amor, el miedo o el enojo? En fin, una revisión y reflexión en torno a los mensajes de estos dos formatos enmarcados en el ámbito del humor, y hoy por hoy, protagonistas en las redes sociales, y los medios de comunicación en general.

Para realizar dicho estudio se revisaron memes y caricaturas, que circularon por las redes, se publicaron en los periódicos, y transitaron todo tipo de medio para su difusión, especialmente en internet. Por lo que el corpus analizado contiene lo que circuló en Facebook, Twitter, Whatsapp, así como, la revisión de una búsqueda de la web de la Red de Movimientos Sociales, y la navegación por internet a través de Google, todo ello del 18 de septiembre al 18 de noviembre. Su selección se realizó con base en su expresión directa o

\footnotetext{
${ }^{1}$ Comentar como curiosidad que, a las $11 \mathrm{~h}$ de ese mismo día, se realizó el "Simulacro" oficial, es decir, un ejercicio cívico para la prevención de una situación de emergencia, y se hace en todo el país ese día, ya que es el aniversario del fatídico sismo de 1985 que asoló la capital. Así que se podría decir que al rato de haber regresado a sus actividades cotidianas todo mundo, es que tuvo lugar este fenómeno, por cierto, esta vez sin la alarma sísmica, pues debido a la proximidad del epicentro a la ciudad esta no se activó.
} 
indirecta sobre el tema. Con posterioridad tuvo lugar un análisis temático según el mensaje transmitido y el movimiento emocional que despierta. Esto es, se focalizó la temática en el tipo de humor -benigno u hostil-, las funciones del humor -alivio, cohesión, expresión, etc.-, y las emociones que conlleva, así como, los subtemas reflejados. Dichas variables surgieron del análisis de la propia revisión, obviamente inspirada en conocimientos y estudios previos sobre emociones, humor y expresiones culturales ante desastres (Fernández, 2011; 2014; 2016).

Aclarar que se reunieron más de medio centenar de expresiones, no obstante, se realizó una selección para presentar en este artículo, el cual contiene 27 ilustraciones, 10 memes y 17 caricaturas. Señalar también que quizás debido a la importancia del terremoto en la Ciudad de México, su elevado número de habitantes, su mayor conexión a internet, muchas de las imágenes aluden a esta urbe, de ahí que hay un sesgo geográfico que parte del material e información existente, sin dejar por ello de reconocer la incidencia de la problemática en otras poblaciones del país en el radio de acción sísmico que tuvo lugar.

Por otra parte, se aplicó una entrevista a administradores de páginas de memes en Facebook con la finalidad de rescatar el discurso y experiencia de estos sujetos protagonistas en el medio, sobre el humor en momentos de desastre en el país, con objeto de complementar la información sobre el tema y la revisión de expresiones humorísticas realizada ${ }^{2}$.

\section{El humor, el meme y la caricatura}

El humor puede ser entendido y estudiado desde lo simbólico (Bergson, 2008) y también lo psicológico como una descarga de energía interior (Freud, 2008), además, como significación social, incluso fuerza transformadora (Bajtin, 1995); si bien también se puede leer como un fenómeno sociológico que apoya en la comprensión de la vida (Berger, 1999), siempre estrategia de comunicación (Raskin, 1985) y expresión emocional, sin lugar a dudas.

De forma resumida, el humor es la percepción subjetiva de lo cómico, un modo de percibir la realidad como graciosa. Pero es más que eso, y como señala Berger (1999) es un descanso en la vida, considerando la risa incluso un acto de redención. Y es que el humor es crítica social, acompañamiento emocional, comunicación política, expresión cultural (Fernández, 2016), e incluso acompañamiento en momentos difíciles de la existencia (Fernández, 2014), y acercamiento solidario como se verá en estas páginas. Mucho se podría decir sobre el humor, pero es más importante señalar su lugar en épocas de catástrofe, y una definición del meme y la caricatura que es de lo que se aborda concretamente en este texto.

\footnotetext{
${ }^{2}$ En este punto quiero agradecer la colaboración de Alberto Mejía en la realización de entrevistas y búsqueda de información en la investigación, así como, en un primer borrador de este trabajo.
} 


\subsection{El humor en tiempos de desastres}

Tras las catástrofes y desastres aparece en ocasiones el humor, ya sea como necesidad de expresión y vinculación al compartir, ya como evasión para transitar emociones desagradables o dolorosas, ya porque el ser humano tiene características y habilidades humorísticas, y las aplica a prácticamente todo en la vida. El humor, expone uno de los administradores entrevistados, "siempre servirá para hacer entendible y digerible la realidad, y en los casos de tragedias más aún, hace más ameno el entorno” (entrevista personal, 25 noviembre, 2019). Eso sí, están desde los chistes blancos o del humor benigno, o incluso afectivo y solidario normalmente relacionados con los sucesos dramáticos, y están los más amargos e irónicos del humor negro o del sarcasmo político en este caso apuntando culpables -causantes del desastre o que han contribuido a ello- o denunciando actitudes y acciones determinadas -tales como la corrupción en los momentos de ayuda posteriores-. En todo caso, se trata de una exacerbación de lo afectivo y agudización de lo creativo en situaciones difíciles y complejas, en momentos de sufrimiento y desasosiego, son parte de las consecuencias psicosociales de los desastres y en parte contribuyen a su recuperación colectiva y cohesión sentimental tan necesaria y bienvenida en esos momentos sumamente estresantes (Fernández, 2014).

Comunicación y emoción se trenzan aún más si cabe estas situaciones, en circunstancias anímicas adaptativas a la realidad donde se desarrolla la resiliencia personal y colectiva tras el shock o trauma inicial y el estrés post traumático que tiene lugar. Las reacciones emocionales -incapacidad de expresar sentimientos, tristeza, miedo, enfado, indefensión y frustración, ansiedad, dolor, apatía-, las cognitivas -incredulidad, negación, confusión, desorientación, sensación de irrealidad, irritabilidad, desconfianza, falta de concentración, sensación de vacío, dificultad de atención o concentración- y las conductuales -hiperactividad, falta de actividad, aislamiento, llanto, dolores, insomnio- son normales ante las experiencias anormales que se experimentan. Así el pánico, la negación y la desconexión suelen aparecer, la huida, parálisis, agitación, confusión, emociones desagradables, insatisfactorias y dolorosas, que intentan reaccionar y adaptarse a lo nuevo (American Psychological Association -AAP-, 2010; (Organización Mundial de la Salud-OPS-, 2003). Por lo que el humor, en su justa medida y del tipo correcto, en el momento y ante la situación específica puede ser una suerte de catalizador emocional que contribuye a la normalización de la anormalidad, siempre por supuesto adecuado y respetuoso.

En el caso del sismo del 19 de septiembre del 2017 se seleccionan caricaturas y memes, como formatos, uno tradicional, otro de más reciente creación, ambos partes de la expresión de lo que acontecía, como necesidad de vehiculizar las emociones, soltar y transitar las vivencias, recordarlas y expresarlas, difundirlas y compartirlas en una comunidad a infinita a la 
velocidad de las redes sociales. Por otra parte, el humor sano heridas, consuela y da energía, como ya se dijo inicialmente. Con lo cual, ante el miedo y el enojo, ante la angustia y la indignación, ante la vulnerabilidad e incertidumbre, o el cambio traumático de las condiciones de vida, el humor comunica, expresa y reconforta, la risa despierta la alegría y expresa el miedo y el enojo -si es el caso-, y es como una caricia al corazón en el sentido que estimula el sistema circulatorio, entre otras cosas, por supuesto.

Así que aquí se revisa los tipos de humor en los memes y las caricaturas, las expresiones y funciones del humor en el desastre alrededor de un hecho específico, así como, las emociones que acompaña, provoca o alivia. Ahora se revisará brevemente qué es una caricatura y un meme.

\subsection{Los memes}

"La única función de un meme siempre será entretener. Si bien, actualmente un meme funciona para satirizar, incluso para criticar, lo cual es bastante útil, jamás deben tomarse más allá" (entrevista personal, 2019). Las anteriores palabras de uno de los administradores de páginas de memes entrevistados son una buena introducción para cuestionarnos el origen teórico de los memes, idea revisada en las siguientes líneas. Propuesto por Dawkins (1993), el concepto de meme es un elemento fundamental para la transmisión cultural entre los sujetos de una sociedad. Utilizando a los genes como paralelo biológico, entiende a los memes como "entidades replicadoras de conceptos", como informaciones virales, "unidades de transmisión cultural" que pasan de sujeto a sujeto, navegación o entramado de ideas y emociones, opiniones y emociones públicas, se podría decir. En fin, unidad mínima de información cultural cuya función social es humor, crítica, hasta mensaje político institucional.

Este término, popularizado por el aumento del uso en redes sociales e internet en los últimos años, ${ }^{3}$ ha sido adoptado para darle sentido al conjunto de imágenes, fotos, videos, canciones, palabras, frases, modas, etc., que se usan cotidianamente dentro de estos medios y cuya finalidad, comúnmente, es provocar placer a través del humor, o también displacer y crítica satírica. Así, es necesario esclarecer que nos enfocaremos en los memes humorísticos de internet, cuya representación más común son las imágenes macro. Estas se constituyen como un "pastiche" con ingenio e ironía (Cortázar, 2014), es decir, como un conjunto de elementos que se combinan para crear una reinterpretación de sus elementos. Surgen, entonces, a partir de la unión de una imagen con un texto y se destacan por su simpleza en recursos estéticos

\footnotetext{
${ }^{3}$ Según la Encuesta Nacional sobre Disponibilidad y Uso de Tecnologías de la Información en los Hogares, el uso de Internet ha estado en aumento en los últimos tres años. En el 2015 eran 62.4 millones las personas usuarias de Internet, el siguiente año fueron 65.5 millones, 2017 fueron 71.3 millones de usuarios de esta tecnología. Respecto al tema de redes sociales, la tendencia está, igualmente, al alta: en 2015, el porcentaje de usuarios que accedían a la Internet para usar redes sociales fue de $71.5 \%$, el siguiente año aumentó a $75.8 \%$ y en el 2017 ya era el $76.6 \%$ (Instituto Nacional de Estadística, Geografía e Información (INEGI), 2018).
} 
y técnicos (baja resolución), mientras utilizan el humor y la burla en conjunto con elementos de la cultura popular, tales como series de televisión, películas o pinturas, entre otras cosas (García, 2014; Cortázar, 2014).

A partir de la modificación de ciertos elementos contenidos en el meme, se provoca un cambio de sentido, surge un nuevo significado, por lo cual puede hallarse sentido entre dos ideas aparentemente inconexas (Radetich, 2006,). Es este momento de sorpresa, en el que lo absurdo de ciertas palabras y frases se cohesionan para darle sentido a un fenómeno de la realidad desde una perspectiva inesperada, que surge la risa (o, por lo menos, la sonrisa). Lo cual tiene que ver con la teoría clásica de la incongruencia aplicada al humor en general y al chiste en particular (Bergson, 2008; Freud, 2008).

Cabe mencionar que, aunque son los menos, hay creadores que se apropian de sus memes a través de marcas de agua o logos que funcionan para puntualizar su origen. La vasta mayoría de memes son anónimos, retoman la tradición de las leyendas y chistes, donde el origen se mantiene desconocido (Alarcón, 2017; Vélez, 2015) lo que facilita su reinterpretación y transmisión.

Lo anterior, puede relacionarse con su funcionamiento como signo. Fundamentalmente, son representaciones de la idea que se quiere dar a entender y funcionan como elementos humorísticos y significativos debido a esto. Solamente tienen una relevancia significativa cuando se relacionan con otros signos que forman parte del mismo sistema (Alarcón, 2017). Así, las transformaciones que sufre un meme lo relacionan con aspectos culturales específicos que se conforman como partes de la ideología de ciertos sujetos. El meme reinterpretado se comparte, poniéndose a disposición de nuevas modificaciones y, por lo tanto, a las posibles identificaciones subjetivas que puedan surgir con estos nuevos sentidos culturales depositados en él. Son, por lo tanto, una pantalla donde se puede apreciar aspectos culturales de cada sociedad, de allí su popularidad. Es sólo cuando estos aspectos cotidianos se muestran a través de la exageración o la parodia que hay una dilucidación de los aspectos cuasi absurdos de la cultura. De esta forma, los memes cuentan con una plasticidad importante y difusión considerable.

Es necesario, entonces, tomar en cuenta otros niveles subjetivos que tienen una dinámica al compartir, modificar y hallar gracioso un meme, por ejemplo, su distribución puede convertirse en un acto que se escabulle en niveles psicológicos relacionados a la vinculación entre pares, o la identificación con un grupo en particular, o puede funcionar como una alternativa a las propuestas humorísticas de los medios de comunicación tradicionales (Cortázar, 2014). Así, es necesario resaltar a los memes como un acto de creatividad que se posiciona como una manera de apropiación de las redes digitales, identificación y hasta dilucidación de los aspectos culturales de un grupo, sin olvidar la comunicación, la emoción, y muchas veces, el humor. Y algo importante en nuestros días, y es que en "la vorágine por consumir 
imágenes encontramos los memes" (Cortázar, 2014, p. 1), por lo que son representantes del tiempo presente.

\subsection{La caricatura}

La caricatura es parte del humor, combina emociones encontradas y mensajes irónicos en imágenes y textos, que mueven a una sonrisa, en alguna ocasión a la alegría, pero muchas veces lo que destaca es la ironía teñida de amargura, especialmente en la caricatura social y política.

Caricatura según el Diccionario de la Real Academia de la Lengua Española (2020) es: "2. f. Dibujo satírico en que se deforman las facciones y el aspecto de alguien. 2. $f$. Obra de arte que ridiculiza o toma en broma el modelo que tiene por objeto.3. f. despect. Obra que no alcanza a ser aquello que pretende" (p.1). El origen etimológico de la palabra proviene del italiano "caricatura" o "caricare" que quiere decir cargar (Pedrazzini y Scheurer, 2012), también se traduce como recargar y exagerar (Curcó, 2004).

Las características de la caricatura son las siguientes (Vergel, 2008): tienen que ver con la simplificación visual, exagerando lo relevante e impacto con trazos mínimos; degradación, agresión y ridiculización; moralidad, pensamiento crítico, defensora de derechos y fuente de denuncias; exageración, deformación de rasgos, gestos, etc.; una opinión y una idea, intencionalidad; deformación de la realidad. Es un juego entre lo visual y textual, imagen y palabra, esto es, inter texto; actualidad, contexto espacio temporal conocido.

En cuanto a su forma y función, la caricatura en general y la social y política, en particular y según Pedrazzini y Scheuer (2012), subraya y exagera la representación gráfica, ridiculiza a personas que deforma, acentúa rasgos físicos del cuerpo o del rostro, trata situaciones de la actualidad y la personalidad caricaturizada, personifica los hechos, siendo responsable de decisiones y acciones políticas que se personifican en ciertos cuerpos y rostros.

El personaje es deconstruido y alterado, exagerado y ridiculizado, dando lugar a la sátira, entrelazando ofensa y comicidad, como parte de la crítica y denuncia de situaciones y asuntos, considerados errores o abusos, siempre desde lo cómico, muchas veces desde lo trágico también.

Sánchez (2012) señala que la caricatura política desarrolla la función crítica de la problemática social existente en un momento dado y hace reír a quien la consume, lo cual colabora a menguar el drama de la política cotidiana. Por su parte, Curcó (2004) pone el acento en que ésta posee un carácter de editorial periodística, esto es, forma opinión, interpreta la realidad de manera humorística e ideológica a través de figuras retóricas de persuasión. 
Su aprehensión en nuestros días es como relato gráfico gracioso, entre irónico y amargo, como se dijo, que se compone de mensaje escrito e icónico. Aúna lenguaje visual y verbal, combina signos lingüísticos, plásticos e icónicos; de hecho, es una expresión icónico-gráfica. En fin, se trata en definitiva de una estrategia de comunicación y de un género periodístico de opinión, cuyo principal objetivo es la crítica, y supuestamente también reflexión, según afirmaba Carlos Monsiváis (Notimex, 2008). A veces predomina la primera, pero muy ideologizada con intención de atacar al adversario. Presenta una suerte de rebelión contra la autoridad en muchas ocasiones, contra el supuesto adversario siempre, a veces sólo una mirada reflexiva a través de un juego de imágenes y palabras, una broma ligera y simpática o una ironía afilada y profunda, en pocas situaciones un acompañamiento amable.

Freud (2008) afirmaba que las caricaturas: "Se dirigen contra personas y objetos respetables e investidos de autoridad (...). La caricatura lleva a cabo la degradación extrayendo del conjunto del objeto eminente un rasgo aislado que resulta cómico, pero que antes, mientras permanecía formando parte de la totalidad, pasaba inadvertido" (p. 203-204). Bergson (2008) señalaba: "Por regular que resulte una fisonomía, por armoniosas que se supongan sus líneas y por ágiles que resulten sus movimientos, jamás es enteramente perfecto su equilibrio. Siempre se desprenderá de ella la indicación de un hábito que se anuncia, el esbozo de un posible gesto, una deformación preferida, en suma, a la cual se inclinará más fácilmente la naturaleza” (p. 27).

Por su parte, Carlos Monsiváis (Observatorio de medios, 2008) opinaba que la caricatura política no es algo que se considere en la actualidad subversivo por quien la observa, sino un instrumento que provoca risa y sobre todo reflexión además añadió que está perdiendo influencia ante el advenimiento y preponderancia de la radio y especialmente la televisión. A lo que habría que añadir los nuevos medios de información producto de las nuevas tecnologías de la comunicación en estos días. No obstante, se mantiene, si bien comparte popularidad con otros medios, tales como el meme de más reciente creación.

En resumen, la caricatura es reflexión, crítica y opinión. Su diversidad incluye desde señalamientos que pueden ser solidarios y afectivos ocasionalmente, hasta la práctica más común que es la sátira política, la cual denuncia, critica, ridiculiza en general a mujeres y hombres políticos, sus dichos, acciones $\mathrm{u}$ omisiones, entre otras cosas.

Se pasa a hora a un contexto sucinto de la situación, con el abordaje de otras tragedias próximas y también tratadas desde las ilustraciones humorísticas, para a continuación centrarse en el objetivo de esta investigación. 


\section{Antecedentes contextuales}

En las siguientes líneas se aborda brevemente las particularidades del humor que surgieron en tres desastres que afectaron de maneras diferentes a la población mexicana, por esas fechas, o sea en ese mismo año -inundación y sismo- o con anterioridad la influenza del 2009. Este ejercicio es una introducción y contextualización temática y expresiva a la situación particular del 19-S.

En primer lugar, el 6 de septiembre calles y avenidas de la urbe sufrieron inundaciones que provocaron el caos en el transporte y la pérdida de automóviles particulares ${ }^{4}$. El humor, en este caso, se presentó a partir de fotografías e ilustraciones que mostraban la ruptura de la cotidianeidad de las personas que diariamente transitan por la ciudad, y reverberan también las aventuras y desventuras del servicio de transporte público (figura 1).

Figura 1. Memes sobre las inundaciones en la CDMX
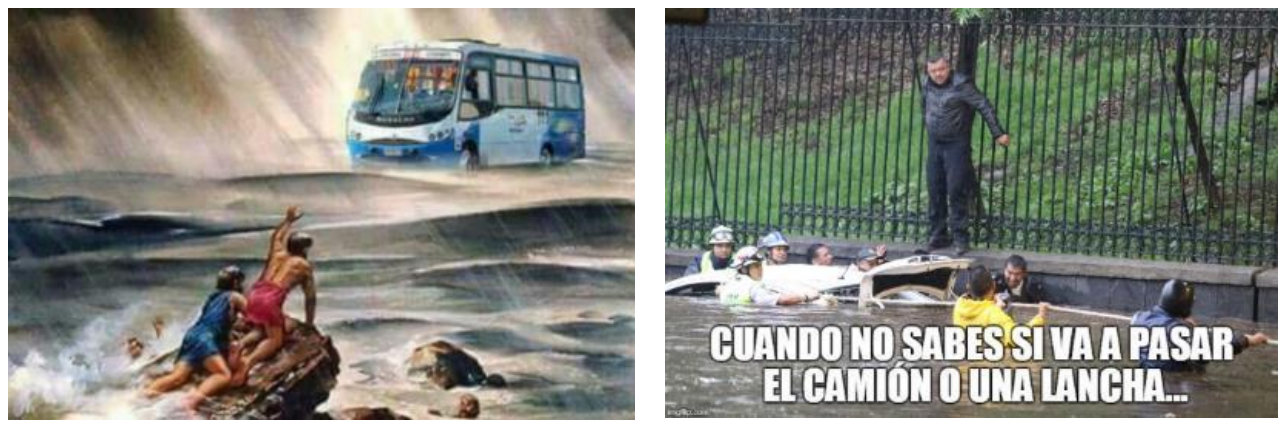

Fuente: https://www.razon.com.mx/secciones/medios/fotos-fuerte-lluvia-genera-ola-dememes/ (2017).

En segundo lugar, el 7 de septiembre del 2017, un sismo de 8.2 grados con epicentro en el Golfo de Tehuantepec sacudió el centro y sur del país ( $\mathrm{SSNb}$, 2017). Oaxaca y Chiapas fueron dos de los estados más afectados. En redes sociales, aparecieron memes que utilizaban el tema del sismo para hacer burla de varios fenómenos circundantes a él; es decir, el humor no surgía de las consecuencias más trágicas del fenómeno (el fallecimiento de personas o el daño patrimonial), sino que funcionaron para la exteriorización del miedo que ocasionan estos fenómenos naturales y sus consecuencias, desde la prevención y cuidado personal, hasta el tradicional humor como crítica política. Lo mismo aconteció con la caricatura.

Desde el lema gubernamental "Estamos moviendo a México" con la imagen del presidente y el añadido "No se asusten" (figura 2), hasta el eslogan "La alerta sísmica de la CDMX es tan buena que avisa un día antes, lo bueno casi no se cuenta, pero cuenta mucho", que es también eslogan institucional, junto a la broma popular, esto debido a que un día antes se disparó la alerta sísmica

\footnotetext{
${ }^{4}$ De hecho, ya en mayo, junio y a finales de agosto del 2017 habían tenido lugar inundaciones en la ciudad y el área metropolitana del Estado de México.
} 
en la ciudad, al parecer por error. No podía faltar el meme de la importancia de llevar alimento canino como parte del kit básico ante un terremoto (figura 2).

Figura 2. Memes que circulaban en las redes sociales
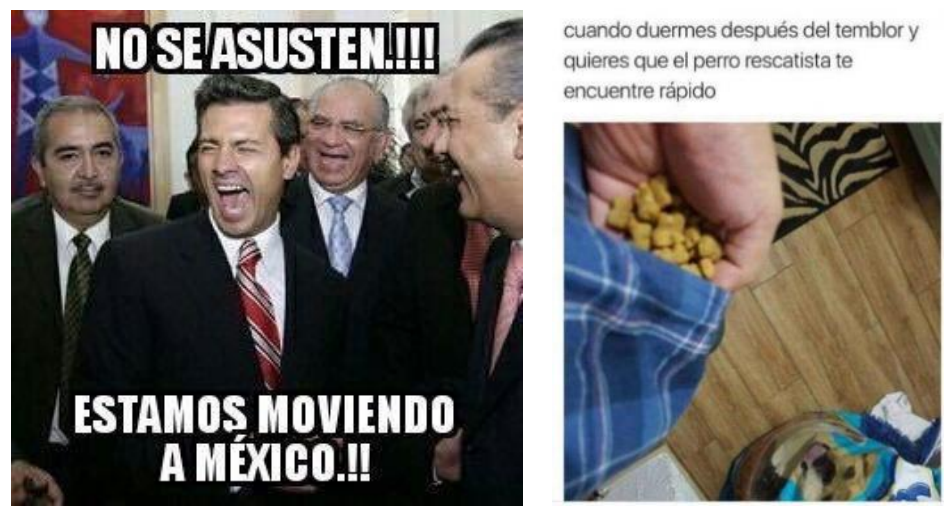

Fuente: Facebook. (2017).

En tercer lugar, se recuerda la influenza (AH1N1) que supuestamente tuvo su aparición en México en la primavera del 2009 y que también fue escenario para el humor. Los chistes, caricaturas e imágenes graciosas en internet que surgieron desde el primer momento, fueron muy variadas y se movieron en los distintos matices del humor, la figura del cerdo y la utilización de la Ciudad de México y sus habitantes como protagonistas, constituyeron elementos ampliamente utilizados para fomentar la burla y la risa (Fernández, 2014). La creación de caricaturas con la temática se acercaba más a la crítica social y política que a la situación misma (figura 3). En ellas se ponía en tela de juicio las acciones de las figuras políticas y se criticaba la información al respecto de la pandemia, incluso se ponía en entredicho su veracidad.

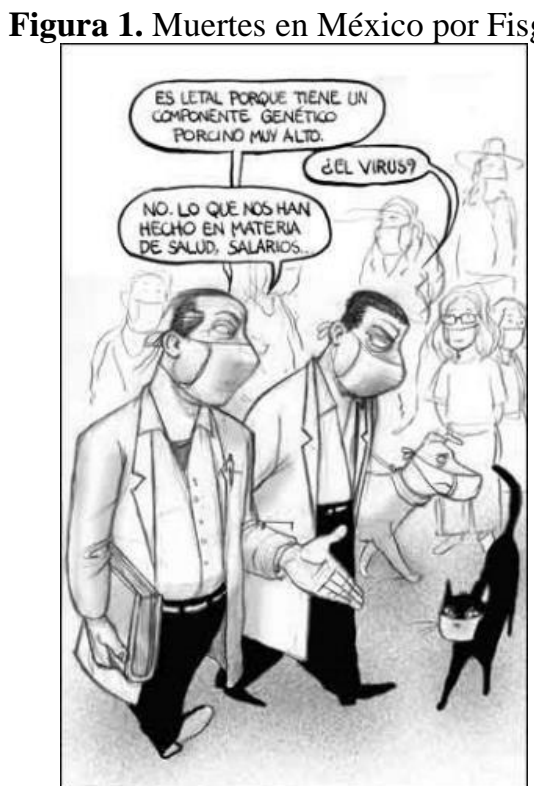

Fuente: https://www.jornada.com.mx/2009/04/28/cartones/1 (2009). 
Tras este enmarcamiento de expresiones humorísticas en catástrofes concretas que asolaron la ciudad en años y días antes del sismo se llega al 19 de septiembre del año 2017.

\section{Análisis y resultados}

Así llegamos al fatídico 19-S. A diferencia de los acontecimientos anteriores, rápidamente se observó la aparición de imágenes que solicitaban que no se crearan memes o bromas sobre el sismo, y fueron estas las primeras en aparecer en las redes sociales y se reiteraron durante los días posteriores de la tragedia. Su formato apelaba a la solidaridad, algunos de ellos a partir del patriotismo (figura 4). Con el uso de la bandera mexicana y el uso de hashtags se pretendía fomentar la empatía entre los habitantes del país. Se podían leer en las redes mensajes como "Oye, tú que puedes leerme, evita por favor hacer bromas sobre el sismo. Siéntete afortunado de estar con vida y poder comunicarlo. Hay gente en el centro de la ciudad que necesita ayuda, no bromas de mal gusto". "La risa es efimera, México es alegre pero comprometido (sic) con la gente ante momentos complicados". Es decir, a través de memes se transmitió el mensaje de petición de petición de no memes que pudieran resultar ofensivos o dolorosos ante la catástrofe. Un menaje que fue un meme en sí mismo.

Ello en paralelo a algunos comunicados oficiales en el mismo sentido, sobre todo un llamado a la unidad, la ayuda ordenada y el no creer en la rumorología se hace eco en las redes.

Figura 2. Imagen que solicitaba no hacer burla sobre las secuelas del sismo.

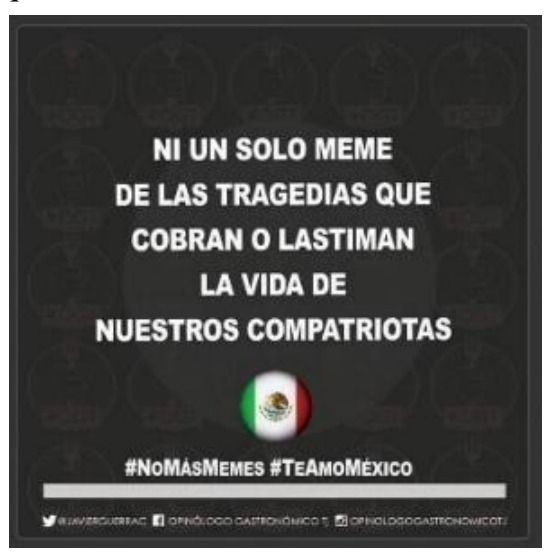

Fuente: Twitter (2017).

Grosso modo, y, para empezar, es posible dividir en dos amplias categorías lo memes y caricaturas que aparecieron en redes sociales y en periódicos en esos días.

Surgieron por un lado las imágenes que apelaban directamente a la solidaridad, la esperanza y a la creación de sentimientos positivos, en el 
sentido de vínculo y afecto social, unidad y hermandad. En éstas, se utilizaba la metáfora visual para mostrar los esfuerzos que estaban realizando los rescatistas y la población en general. Así, en compañía de símbolos, tales como el Ángel de la Independencia, el mapa de la República Mexicana y la bandera, así como la figura de la muerte enfrentada a la solidaridad (figura 5), se representaban las acciones que cientos de personas realizaban para ayudar a las personas afectadas más directamente. Manos unidas en los escombros (figura 6), picos, cascos y palas de los rescatistas, símbolos de esperanza, solidaridad y vida, sobre escenarios de destrucción, donde sobresale la expresión de amor, ante incluso la presencia de la muerte (figura 7).
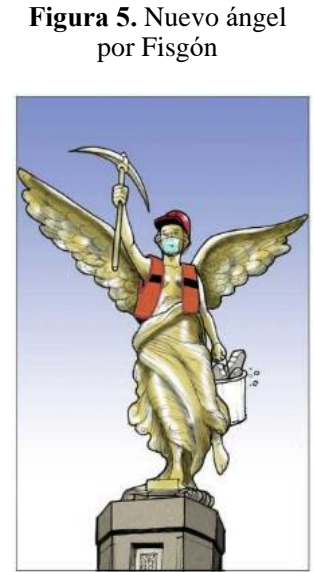

Figura 6. Solidaridad ante el sismo por Rocha

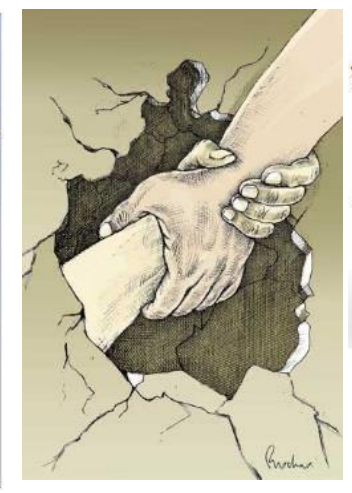

Figura 7. Disputa por Helguera

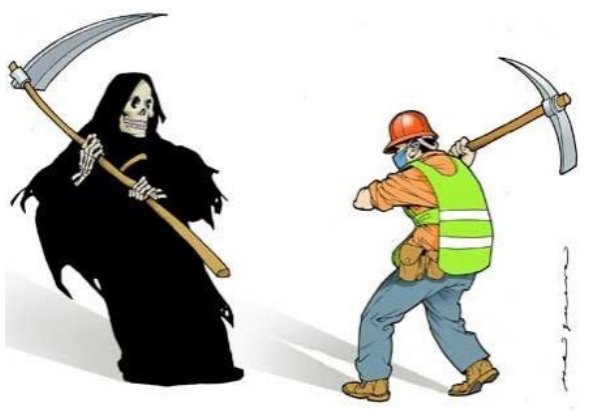

Fuente: http://www.redmovimientos.mx/2016/cartones/ (2017).

Por otro lado, están quienes apelaban a la crítica y a la disconformidad. Utilizaban al sismo como un telón de fondo para la burla agridulce de otros asuntos que lo rodeaban. En estas imágenes, el humor no surgía de la tragedia misma, sino del papel que jugaban los medios de comunicación y los actores políticos durante el evento o con relación a sucesos acontecidos con anterioridad. Todo dentro de la tradicional crítica político-humorística, donde amargura, enojo y miedo se entrecruzan (figura 9).

Figura 8. Mexico football stars help building the city after the earthquake por Omar Momaní

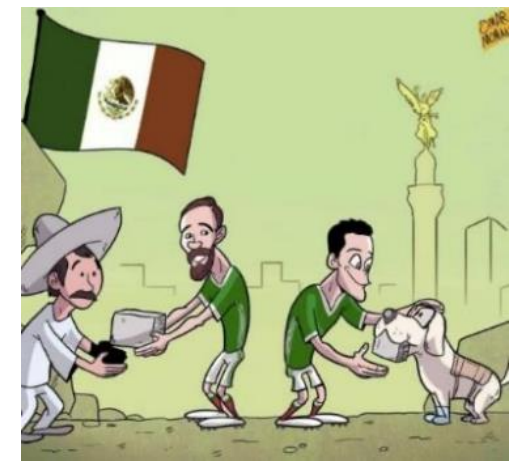

Fuente: http://omarmomani.blogspot.com/2017/09/ (2017).
Figura 9. Cartón por Julio César

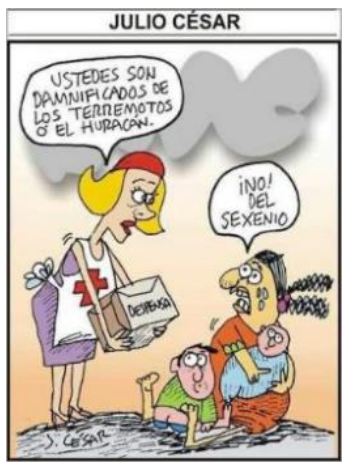

Fuente: https://bit.ly/2HsyDMi 
En ambas categorías, se piensa que quizás y en el fondo, la función principal era la misma: fomentar la solidaridad (figura 8). Una de forma directa, la otra no tan clara, una desde la esperanza y el entusiasmo propositivo, la otra traspasada por la inseguridad, la ira, entre la crítica y la desolación. El sismo, como un evento fuera del "dominio humano", dirigió la atención a lo que sí podía estar bajo el control de los sujetos o actoras sociales, por lo tanto, las acciones de las figuras públicas estaban sometidas a un escrutinio pormenorizado, a través de la crítica, la ciudadanía podía dirigir sus emociones a las fallas de un "enemigo en común", responsable sino del suceso, sí de su prevención y reparación ante la vulnerabilidad creada (figura $10,11)$.

Figura 10. Simple pregunta por Fisgón

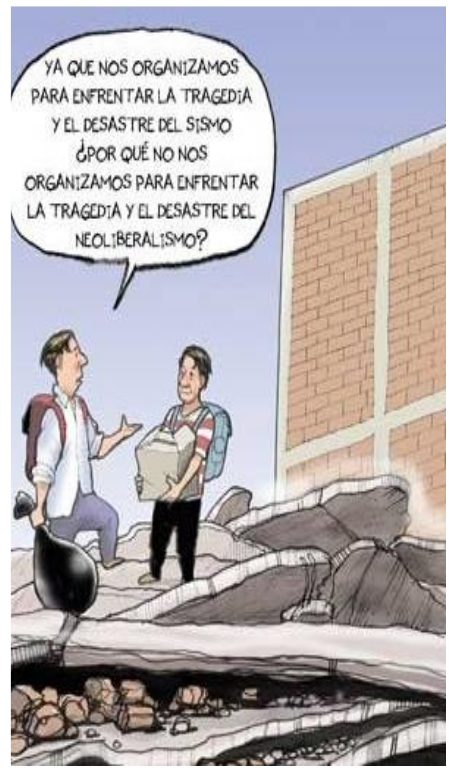

Fuente: http://www.redmovimientos.mx/2016/cartones/ (2017).

Esta función o intención de vínculo y solidaridad, se percibe con facilidad en la primera categoría, el uso de símbolos para la identificación del apoyo que ejerció la población creaba esperanza ante la catástrofe y ayuda para las personas afectadas.

En particular, muchos de los memes que se generaron en los días posteriores al sismo tuvieron como protagonistas principales a los perros de la Unidad Canina de la Secretaría de Marina de México. De manera irónica también se utilizaba su imagen para hacer burla de temas generales y, particularmente, de las acciones del gobierno y la posibilidad, siempre latente, de que su papel fuera solo una mera distracción ante la tragedia; muestra de la desconfianza y rencor político social existente (figura 12) ${ }^{5}$.

\footnotetext{
${ }^{5}$ Frida, una perra rescatista muy popular en los medios.
}

Figura 11. Corrupción por Rictus

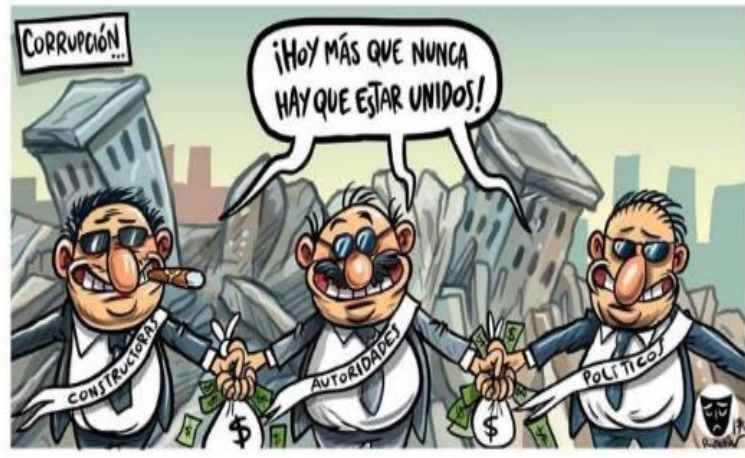


Figura 12. Memes sobre los perros rescatistas

Captaron a Frida cobrando todo lo que le pagó el PRI para distraer al pueblo.
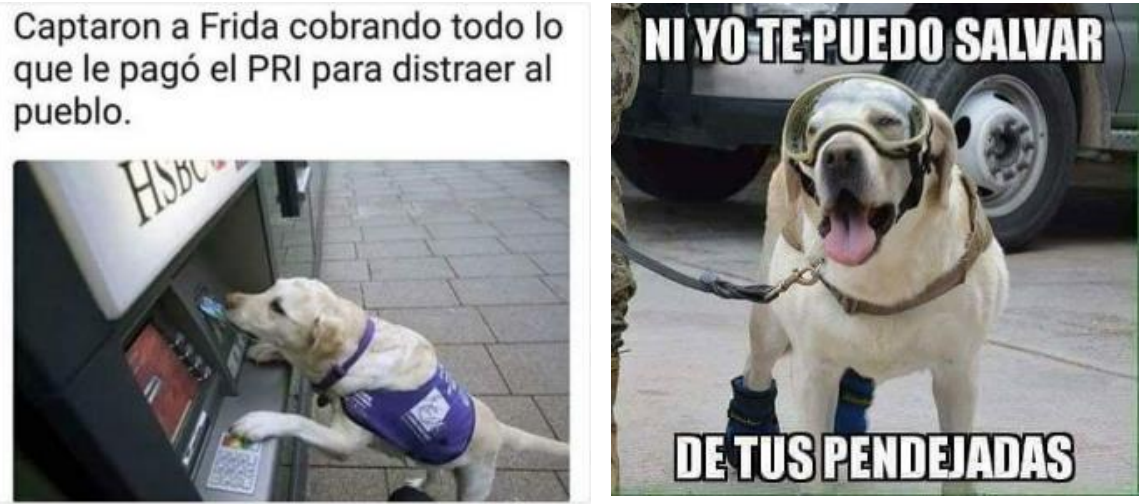

Fuente: Facebook (2017).

No obstante, la mayoría insistimos, de las caricaturas y memes sobre canes rescatistas fueron alardes de cariño, solidaridad y afecto esperanzador entre animales y, sobre todo, hacia los humanos (figura 13, 14).

Figura 13. Dibujo de Frida por GarabuGus

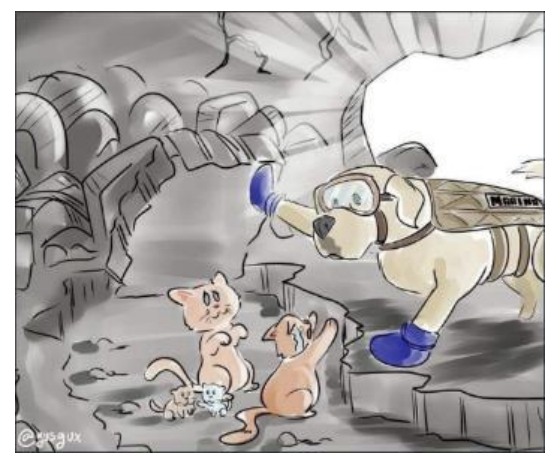

Fuente:

https://twitter.com/Gusgux/st atus/909955166962626560

(2017)
Figura 14. Dibujo por Miss Kanto

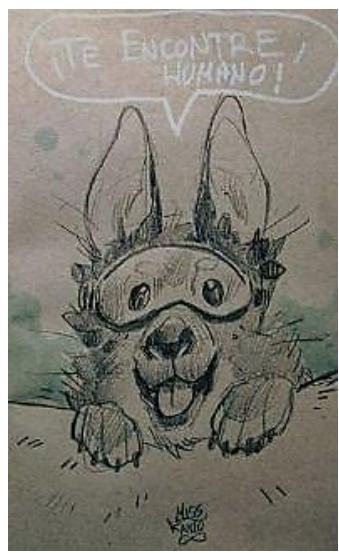

Fuente:

https://www.facebook.com/misskantoartz/photos/a.1491 $\underline{458174443429 / 1942454306010478 / \text { ?type }=3 \& \text { theater }}$ (2017).

Incluso memes que aunaban el testimonio y el sentimiento solidario a la par que el enojo y crítica añeja; en una suerte de hibridación de ambas posiciones socio políticas y emocionales presentes en el momento. La crítica al presidente Enrique Peña Nieto (figura 15), por cierto, muy protagónico en el mundo de los memes ${ }^{6}$, durante su sexenio (2012-2018), no podía faltar. La búsqueda de personas con vida en los escombros sobre el mapa de México y un corazón en el centro del país (figura 16), desde una postura humanitaria, simbólica y sentida por todo mundo en esos precisos momentos.

\footnotetext{
${ }^{6}$ Tanto así, que cuando dejó la presidencia, hubo memes de despedida e incluso le nombraron el rey de los memes.
} 
Figura 15. Meme que circulaba en redes

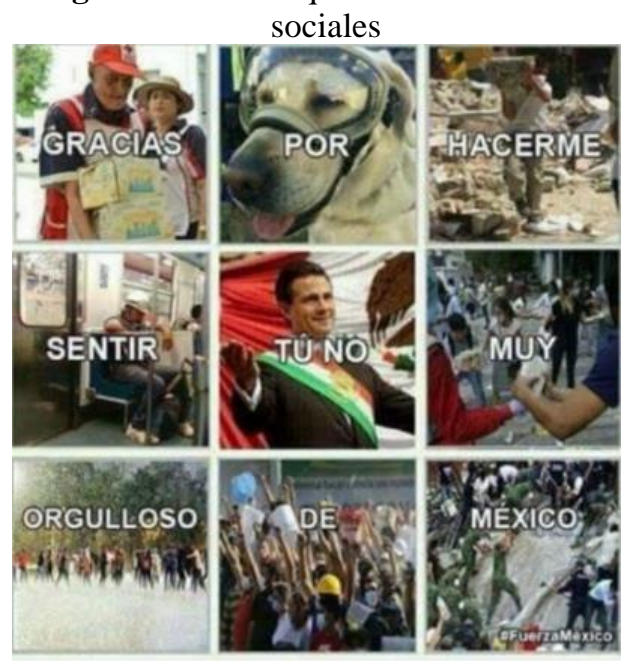

\section{Fuente:}

http://eldeforma.com/2017/10/03/losmejores-memes-y-reacciones-al-emoji-defrida-la-perrita-rescatista/ (2017).
Figura 16. Solidaridad por Acelo Ruíz

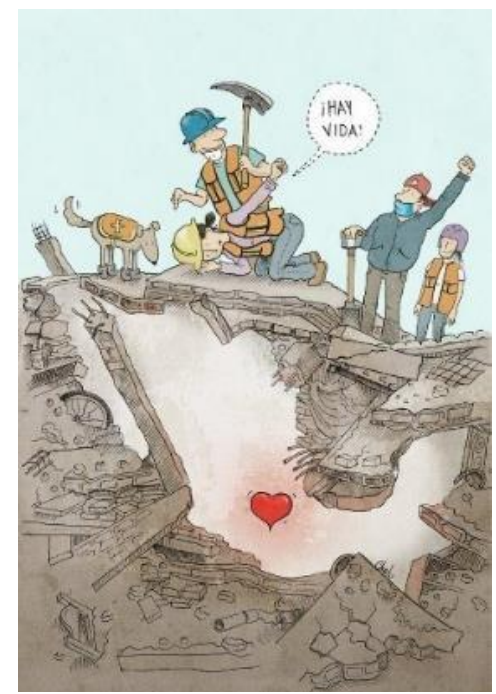

\section{Fuente:}

https://twitter.com/aceloruiz/status/9112 55279962124294 (2017).

Otro aspecto es como la solidaridad hermanó causas, ya que el terremoto aconteció 7 días antes del aniversario número 5 de los desaparecidos de Ayotzinapa (figura 17) ${ }^{7}$ y 13 antes que la conmemoración 49 de la matanza del 2 de octubre (figura 18$)^{8}$, si bien aquellas fueron políticas y sociales, y el sismo supuestamente natural, supuestamente porque quizás la humanidad tenga responsabilidad en el daño al planeta, y las personas y gobierno en la creación de vulnerabilidad al no seguir las normas oficiales en las construcciones, entre otras cosas.

Figura 17. Las tragedias de septiembre por Qucho

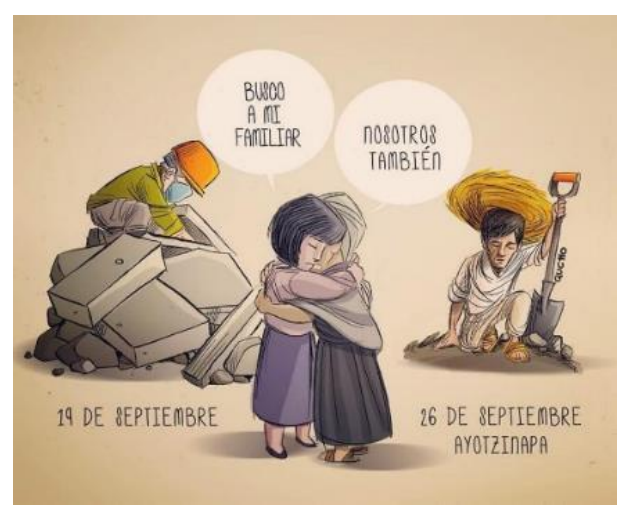

Figura 18. Recordatorio Millenial por Rocha

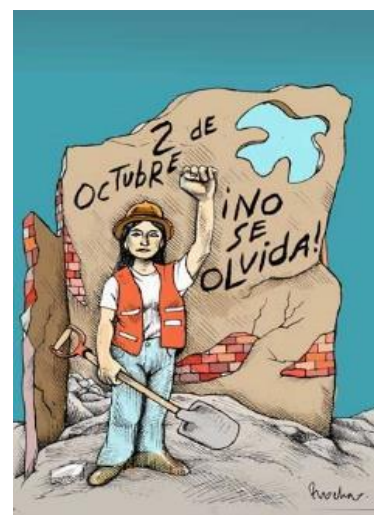

Fuente: http://www.redmovimientos.mx/2016/cartones/ (2017).

\footnotetext{
${ }^{7}$ Se refiere a la desaparición forzada de 43 estudiantes normalistas en Iguala, Guerrero, el 26 de septiembre del año 2014.

${ }^{8}$ Los hechos de la matanza de estudiantes el 2 de octubre de 1968 en Tlatelolco, Ciudad de México.
} 
No hay que olvidar algunos videos donde las personas que se movían al compás del temblor, intentando guardar el equilibrio y no caer, fueron musicalizados como el del "Payaso de rodeo" (https://www.youtube.com/watch?v=ry43CmUCIOQ). Y cómo este, otros más circularon en internet, conjuntamente con los que transmitían una y otra vez las destrucciones, caídas de edificios, carreras de la gente, la tragedia en vivo y a todo color, se repetía una y otra vez en las pantallas.

Es preciso también recordar los memes y caricaturas que jugaban con el "malentendido" o "confusión" según la Marina y Televisa en el caso de la niña del colegio Rébsamen, que conmovió a México y al mundo, o por lo menos a quien tenían acceso a la señal televisiva y a los medios electrónicos por esas fechas, ya que algunas colonias permanecieron algunas horas y otras incluso días, sin energía eléctrica. Frida Sofía, una posible sobreviviente enterrada viva bajo los escombros de su escuela en Tlalpan, al sur de la ciudad de México, donde murieron 19 niños y 7 adultos, fue la protagonista "fantasma" que tuvo en vilo a muchos, para luego descubrirse que no había existido nunca. Caso que recuerda al de Monchito 32 años atrás, un 19 de septiembre de 1985, fechas fatídicas para la historia de México ${ }^{9}$, un infante del que se creía quedó atrapado en las ruinas del centro de la trama urbana y que al parecer se trató de una falsa noticia.

Es interesante destacar el caso de "Frida Sofía". Este fenómeno mediático retrató el intento de rescate de una niña, que supuestamente se encontraba debajo de los escombros de su escuela. La transmisión acaparó la atención de gran parte de la población y tras horas de tensión e incertidumbre se confirmó que todo había sido un "error" y que Frida Sofía nunca había existido (figura 19). Lo anterior es interesante por dos razones, en primer lugar, es inevitable resaltar los paralelismos que existen entre este caso y el de "Monchito" que de igual forma, trató sobre los intentos de rescate de un niño atrapado en las ruinas de un departamento ubicado en la calle de Venustiano Carranza. Al contrario del caso del 2017, existen varias fuentes que explican que el niño sí existió y que días después fue hallado sin vida, pero el consenso general es que fue un fenómeno surgido a partir de la histeria colectiva. La segunda razón, y que más nos atañe, es el humor que surgió a partir de que se confirmara que "Frida Sofía" había sido la protagonista fantasma de una historia surgida por un malentendido ${ }^{10}$. Memes y caricaturas criticaban el papel de la Secretaría de Marina y la manera en cómo diferentes medios de comunicación, principalmente Televisa, habían utilizado la historia para aumentar los niveles de audiencia en su cobertura del sismo. Igualmente, las comparaciones entre las dos Fridas, la niña y la perra

\footnotetext{
${ }^{9}$ Recordar lo dicho, el 19 de septiembre de 1985, 32 años antes, la ciudad también sufrió un fatídico sismo de magnitud 8,1 y se habla de más de 10,000 muertos, según la Cruz Roja, si bien el gobierno lo estimó en algo más de 3,000. En todo caso la fatalidad del día hace imposible no pensar en la memoria y comparar lo sucedido (Allier, 2018).

${ }^{10}$ Se dice que fue error, pero también pesa la sombra de sospecha de un montaje televisivo.
} 
rescatista -anteriormente mencionada-, jugaban con la idea de la presencia y relevancia de una y la ausencia de la otra -la niña- (figura 20).

Figura 13. Infaltable por Helguera.

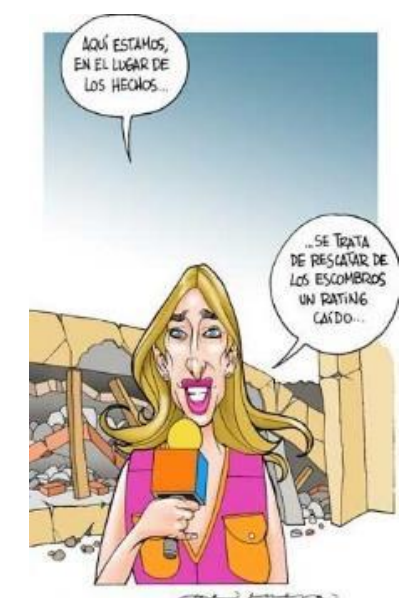

Fuente:

http://www.redmovimientos.mx/2016/cart ones/ (2017).
Figura 4. Meme que circulaba en las redes.

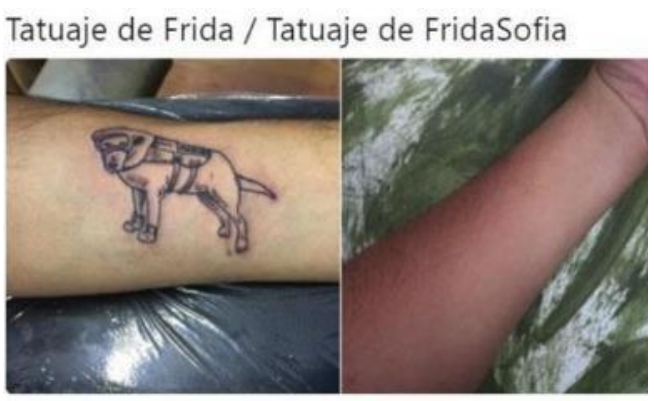

Fuente:http://eldeforma.com/2017/10/03/1 os-mejores-memes-y-reacciones-al-emojide-frida-la-perrita-rescatista/ (2017).

En fin, que caricaturas y memes se nutrieron de las noticias del momento, ya fueran estas verdaderas o falsas, y jugaron con la evocación de una estimada y popular canina adiestrada para rescates, la perra Frida, y el fantasma -pues resultó inexistente- de una niña supuestamente llamada Frida Sofia que estuvo atrapada durante horas en la mente de las personas que seguían el espectáculo televisivo que se montó ${ }^{11}$.

\section{Conclusiones}

Tras una catástrofe o desastre que causan desequilibrio emocional y desórdenes mentales, algo que se aconseja -además de no ver noticias tendenciosas, tener información precisa, incorporarse a la vida normal, mantenerse ocupados psicológica y físicamente, comunicarse con familiares y amigos, refugiarse en sus creencias, expresarse artística o escrituralmente, o compartir verbalmente- es mantener en la medida de lo posible el sentido del humor (Fernández, 2014), así como, el equilibrio emocional y la salud mental.

Al parecer, esto fue lo que aconteció tras el sismo del 19-S de 2017, como dijo un entrevistado: "Asumimos un papel de usuario responsable -expone uno de nuestros entrevistados- (...) El número de personas compartiendo información relevante fue demasiado elevado. Fue un trabajo en equipo, debo decir. Así que, en resumen, ese día fuimos maduros, ese día decidimos unirnos para hacer info (sic) útil" (entrevista personal, 22 noviembre, 2019).

\footnotetext{
${ }^{11}$ La cuestión es más que dura pues esto tuvo lugar en los escombros de un colegio donde fallecieron 19 infantes.
} 
Si bien hubo características precisas en cuanto al tipo de humor -benigno en torno a los hechos, y negro o agresivo con relación a la crítica política, a quienes se aprovechaban de las circunstancias o no actuaban la altura de las mismas, incluso azuzando antiguos rencores- y con determinadas expresiones sobre su funcionalidad social de distanciamiento, descarga y adhesión (Fernández, 2016). También es posible afirmar que abundaron caricaturas sino series estrictamente hablando, sí respetuosas, cuando no cálidas, en el sentido de un uso diferente al habitual. Lo mismo aconteció con los memes, pues al inicio desde el propio formato se solicitó no hacer mofa ni memes sobre la tragedia.

Medios y expresiones tradicionales de burla y crítica, se trocaron en mensajes de amor y solidaridad, en muchas ocasiones, y fluyeron por los medios y las redes con mensajes empáticos y cariñosos.

El humor comunica, expresa, acerca y vincula a las personas, al mismo tiempo que estas toman cierta distancia del problema que existe (Berger, 1999). El humor y la risa descarga la energía psíquica y física (Freud, 2008). Por lo que en momentos de alto estrés y mucho dolor contribuye sino a desaparecerlo, sí a sobrellevarlo, adaptarse y transitarlo. Quizás evitan el contacto con el problema en cierta manera o durante determinado tiempo, quizás disminuyen su intensidad o incluso la niegan, tal vez suplantaron otros sentimientos como la ansiedad y el coraje o la tristeza. Y quizás también aumentaron la frustración y la ira ante el sarcasmo y la ironía cuando entraba en acción la intención política del meme o la caricatura más allá del desastre en sí. Tal vez la caricatura por su mismo carácter de constituirse como crítica política enfatizó más dicha vertiente contra políticos e inmobiliarias, el neoliberalismo o la pobreza. También se retrajo la burla y la ironía y el afecto emergió, en parte y por unos días. Una suerte de desapego ante la tragedia, poder ante la adversidad, trascendencia de la cotidianeidad traumática, una tabla de salvación que hace como señala Berger (1999) la vida más soportable, y en el caso del tema que se aborda, y para algunos tipos de humor, la creación de cohesión de grupo (Martin, 2008), como parte de la configuración de emociones positivas (Fredrickson, 2004) importante en la construcción de resiliencia en esos momentos de emergencia.

Hasta aquí la revisión de memes y caricaturas, sus tipos, expresiones y funciones durante los días siguientes al 19-S. Decir a modo de balance crítico y reflexivo que ambas expresiones son comunicación en vivo y en directo, y si bien se diferencian por el anonimato de unos y la autoría de las otras, y el que los primeros son hijos de las redes y las segundas parte de la prensa escrita, en esta ocasión todo navegó por internet también. Ambas comunicaron como función principal, la importancia de la expresión de opinión, emocional, identitaria. Las dos crearon comunidades que se entretuvieron, solidarizaron, criticaron, apoyaron en torno a una problemática social actual (Sánchez, 2012), a partir del ingenio y la ironía (Cortázar, 2014), 
imágenes icónicas y textos escritos que expresaban y vinculaban, descargaban y sosegaban. Un humor a veces suave, más afectivo que risueño, en ocasiones más amargo que divertido. Una expresión, que como ya se dijo con anterioridad, fue más que nada y, sobre todo, una caricia al corazón, que más que la estimulación del sistema circulatorio, proporcionaron energía y ánimos, y en buena parte de los casos, afecto y vínculo, fortalecieron unión y acción propositiva y solidaria, tan necesaria en medio de la contingencia.

Caricaturas y memes -expresiones de la cultura popular- crónica social, acontecimientos importantes, testimonios anónimos o firmados, ofrenda de amor y odio. Y es que en esos días en las calles y en las redes se trenzaron opiniones y emociones, no podía ser de otra manera ante la conmoción vivida en primera persona, la experiencia o conocimiento de la tragedia.

Figura 1. El sismo de los partidos por Tiscareño

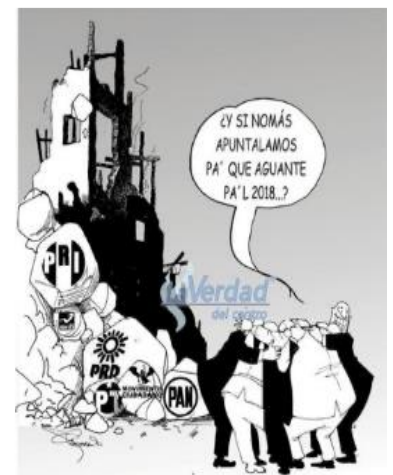

Fuente:

http://www.laverdaddelcentro.com.mx/leer20405-el-carta-n-de-tiscarea-o-el-sismo-delos-partidos.html (2017).
Figura 2. La moderna ciudad por Magú

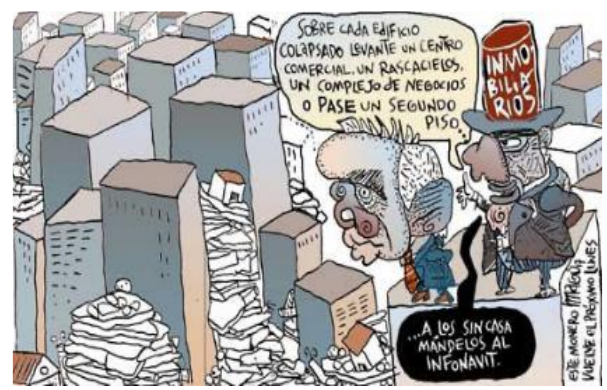

Fuente:

http://www.redmovimientos.mx/2016/cartones/ (2017).

Siempre se ha dicho que dos son las emociones principales, el amor y el temor. El primero con las víctimas más directamente afectadas creó unión y afecto positivo, trajo solidaridad y consuelo. El segundo miedo por las circunstancias de la posibilidad que se repita el sismo, y sobre todo enojo hacia los culpables en el sentido de la vulnerabilidad de las construcciones por no cumplir ciertas medidas de protección. Las caricaturas expresan y comparten emociones, sin embargo y pese a la participación de la audiencia y la complicidad de ésta, son los memes quienes destacan lo de compartir y expresar emociones de ida y vuelta. Los memes, comunicación intersubjetiva e intergrupal, transportaron emociones de amor y miedo -incluido el enojo-, y las consecuencias psico sociales y socio políticas de la ciudadanía, vinculando, quizás soltando tensión, tal vez reequilibrando sensaciones y emociones. 
Figura 23. Aún respira por Fisgón

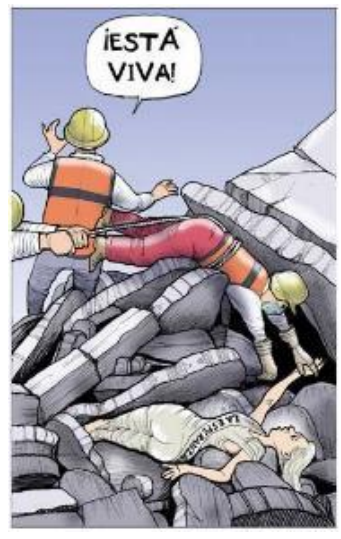

Figura 24. Un rescatista en cada hijo te dio por Rocha

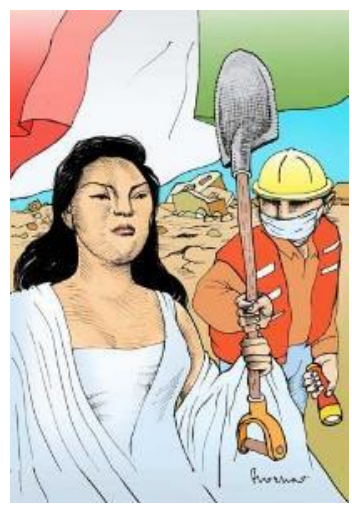

Fuente: http://www.redmovimientos.mx/2016/cartones/

Lo que sí es posible afirmar para este caso en particular es que caricaturas y memes que son usualmente expresión y fuentes de humor, ahora se bañaron de afecto, solidaridad y unión, compasión y amor, ante el sismo, y eso fueron lo que difundieron. Aunque también apareció el humor con ironía, amargura, enojo, el humor político, que criticaba los partidos, el gobierno, el robo de donaciones, la corrupción, el lucro de las constructoras, incluso la vulnerabilidad y la pobreza ante desastres tales como un sismo. Así hubo afecto y vinculación, y hubo también crítica agridulce y enojada.

\section{Referencias Bibliográficas}

Alarcón, V. (2017). Humorismo como creación y fortalecimiento de los vínculos en la sociedad red: el caso de los memes sobre filósofos. Revista de Comunicación 16(1), 122-146. Recuperado en: http://www.revistadecomunicacion.com/pdf/2017_1/6_Art122-146.pdf

Allier, E. (2018). Memorias imbricadas: terremotos en México, 1985 y 2017. Revista Mexicana de Sociología, 80. Recuperado de http://www.scielo.org.mx/scielo.php?script=sci_arttext\&pid=S01882503201800 $\underline{0500009}$

American Psychological Association (APA). (2010). Manejando El Estrés Traumático: Consejos para Recuperarnos de un Desastre Natural. Recuperado de https://www.apa.org/centrodeapoyo/consejos-desastres

Bajtin, M. (1995). La cultura popular en la Edad Media y el Renacimiento. El contexto de Francois Rabelais. Madrid: Alianza Universidad.

Berger, P. (1999). La risa redentora. La dimensión cómica de la experiencia humana. Barcelona: Kairós. 
Bergson, H. (2008). La risa. Ensayo sobre la significación de lo cómico. Madrid: Alianza Editorial.

Cortázar, A. (julio, 2014). Imágenes rumorales memes y selfies: elementos comunes y significados. Revista de Ciencias Sociales y Humanidades,35(77). Recuperado de: https://revistaiztapalapa.izt.uam.mx/index.php/izt/article/view/149/300

Curcó, C. (septiembre, 2004). Ironía, persuasión y pragmática: el caso de la caricatura política mexicana contemporánea. Acta Poética, 25(2), 333-375.

Dawkins, R. (1993) Memes. En El gen egoísta (pp.215-233). Barcelona: Salvat Editores.

Dawkins, R. (diciembre, 2014). Desastres sociales, chistes culturales y risas emocionales. Tecsistecatl, Economía y sociedad de México, 6(17). Recuperado de: http://www.eumed.net/rev/tecsistecatl/n17/cultura.pdf

Dawkins, R. (2016). Humor en el aula. México: Trillas.

Fernández, A. M. (junio, 2011). Antropología de las emociones y teoría de los sentimientos. Versión, 26, 1-24. Recuperado de www.annamariafernandezponcela.com

Fernández, A. M. (2014). Desastres sociales, chistes culturales y risas emocionales. Tecsistecatl, Economía y sociedad de México, 6 (17), 1-30. Recuperado de: http://www.eumed.net/rev/tecsistecatl/n17/index.htm

Fernández, A. M. (2016). Humor en el aula. México: Trillas.

Freud, S. (2008). El chiste y su relación con lo inconsciente. Madrid: Alianza editorial.

Fredickson, B. L. (julio, 2004). El poder de los buenos sentimientos. Mente y cerebro, $8,74-78$.

García, D. (marzo, 2014). Las imágenes macro y los memes de internet: posibilidades de estudio desde las teorías de la comunicación. Paakat: Revista de Tecnología y Sociedad, 6(4). Recuperado de: http://www.udgvirtual.udg.mx/paakat/index.php/paakat/article/view/217/316

Instituto de Investigaciones Legislativas (IIL). Sismo 19 de septiembre 2017: Aspectos estadísticos, financieros y sociales relativos a la reconstrucción, recuperación y transformación de la CDMX. Recuperado de: https://congresocdmx.gob.mx/media/banners/d120319-2.pdf

Instituto Nacional de Estadística y Geografía (INEGI). (febrero, 2018). Comunicado de prensa núm. 105/18. En México 71.3 millones de usuarios de internet y 17.4 millones de hogares con conexión a este servicio: ENDUTIH 2017. Recuperado de:

http://www.beta.inegi.org.mx/contenidos/saladeprensa/boletines/2018/OtrTemE con/ENDUTIH2018_02.pdf 
Martin, R. A. (2008). Psicología del humor: un enfoque integrador. Madrid: Orión.

Notimex. (28 de marzo de 2008). Provoca el cartón político en México risa y reflexión: Monsiváis. El Universal.mx. Recuperado de: http://archivo.eluniversal.com.mx/notas/493721.html

Organización Mundial de la Salud (OMS). (2003). La salud mental en las emergencias. Aspectos mentales y sociales de la salud de poblaciones expuestas a factores estresantes extremos. Recuperado de: https://www.who.int/mental_health/resources/mhe.pdf

Observatorio de medios UIA (2008). El Universal online difunde: Provoca cartón político en México risa y reflexión: Monsiváis. Recuperado de: http://observatoriomediosuia3

Pedrazzini, A y Sheuer, N. (2012). Figuras retóricas verbales y visuales en la conformación de un estilo de autor: las caricaturas políticas del seminario satírico francés Le Canard enchaîné. Cultura, lenguaje y representación, 10, 111-128.

Real Academia Española. (2020). Catástrofes, Desastres, Risa, Humor, Chiste. Recuperado de: https://dle.rae.es/caricatura

Radetich, N. (2006). La risa y el quebranto. México: CONACULTA-FONCA.

Raskin, V. (1985). Semantics Mechanisms of Humor. Holland: Reidle Publishing Company.

Sánchez, G. (2012). La caricatura política: sus funcionamientos retóricos. Razón y Palabra, $78 . \quad$ Recuperado de: http://www.razonypalabra.org.mx/varia/N78/2a\%20parte/28_Sanchez_V78.pdf

Servicio Sismológico Nacional (SSN). (2017a). Reporte especial: Sismo de Tehuantepec (2017-09-07 23:49 Mw 8.2). Recuperado en: http://www.ssn.unam.mx/sismicidad/reportesespeciales/2017/SSNMX_rep_esp_20170907_Tehuantepec_M82.pdf

Servicio Sismológico Nacional (2017b). Reporte Especial. Sismo del día 19 de Septiembre de 2017, Puebla-Morelos (M 7.1) Recuperado de http://www.ssn.unam.mx/sismicidad/reportesespeciales/2017/SSNMX rep esp 20170919_Puebla-Morelos_M71.pdf

Ureste, M. (2017). Lo que el \#19S nos dejó: víctimas, daños y damnificados. Animal Político, 19 octubre. Recuperado de https://congresocdmx.gob.mx/media/banners/d120319-2.pdf

Vélez, J. (2015). Influyendo en el ciberespacio con humor: memes y otros fenómenos. Versión. Estudios de Comunicación y Política, 35. 130-146. Recuperado de: http://version.xoc.uam.mx/tabla_contenido.php?id_fasciculo=696

Vergel, L.P. (2008). Imágenes de la caricatura política en época electoral: campaña presidencial 2001 (Tesis de licenciatura, Universidad Nacional Mayor de San 
Marcos,

Lima).

Recuperada

de:

http://cybertesis.unmsm.edu.pe/handle/cybertesis/1288 